\title{
Maternal Sociodemographic Parameters: Impact on Trace Element Status and Pregnancy Outcomes in Nigerian Women
}

\author{
Emmanuel I. Ugwuja', Emmanuel I. Akubugwo ${ }^{2}$, Udu A. Ibiam ${ }^{3}$, and Onyechi Obidoa ${ }^{4}$ \\ 'Department of Chemical Pathology, Faculty of Clinical Medicine, Ebonyi State University, PMB 053 Abakaliki, Nigeria, ${ }^{2}$ Department \\ of Biochemistry, Abia State University, Uturu, Nigeria, ${ }^{3}$ Department of Biochemistry, Faculty of Biological Sciences, Ebonyi State \\ University, PMB 053 Abakaliki, Nigeria, and ${ }^{4}$ Department of Medical Biochemistry, University of Nigeria, Nsukka, Nigeria
}

\begin{abstract}
To determine the impact of socioeconomic status on plasma trace element status and pregnancy outcomes, 349 pregnant women, aged 15-40 years (mean $27.04 \pm 2.75$ years), recruited at $\leq 25$ weeks (mean $21.76 \pm 3.12$ weeks) gestational age, were followed up till delivery during which maternal and foetal outcomes were recorded. Plasma copper, iron, and zinc were determined using atomic absorption spectrophotometer while maternal sociodemographic data were obtained using a questionnaire. Except for copper, lower plasma iron and zinc were significantly $(\mathrm{p}<0.05)$ higher in women from socioeconomically-disadvantaged groups. Both adverse maternal health and foetal outcomes also seemed to be more prevalent in socioeconomically-disadvantaged women, although without a definite trend. This study has shown that, in economically-disadvantaged setting of developing countries, maternal socioeconomic status impacts on maternal trace element (copper, iron, and zinc) status and health and foetal outcomes.
\end{abstract}

Key words: Maternal nutrition; Morbidity; Pregnancy outcomes; Socioeconomic status; Trace elements; Nigeria

\section{INTRODUCTION}

Maternal socioeconomic status and non-modifiable, non-biological factors that affect mental and physical well-being (1) have been associated with maternal nutrition and pregnancy outcomes $(2,3)$. Although it is increasingly acknowledged that societal factors play a significant role in micronutrient status and pregnancy outcomes $(1,3)$, studies on impacts of socioeconomic status on pregnancy outcomes have produced conflicting results $(4,5)$. For instance, the risk of preterm birth has been reported in mothers of low socioeconomic status (6). In Danish and Norwegian populations, the risk of preterm birth was reported to have an inverse association with educational level of mothers (7). Morgen et al. did not find any association between

Correspondence and reprint requests should be addressed to:

Dr. Emmanuel I. Ugwuja

Department of Chemical Pathology

Faculty of Clinical Medicine

Ebonyi State University

PMB 053 Abakaliki

Nigeria

Email: ugwuja@yahoo.com risk of preterm birth and other indicators of socioeconomic status, such as household income and parental occupation (2). A study in Germany found that women with the lowest level of education had a significantly-elevated risk of small-for-gestational age newborns compared to women with the highest level of education (8), with the distribution of factors known to influence intrauterine growth varying with educational level. There has also been controversy over the influence of unemployment in the family on pregnancy outcomes. While some studies have shown associations of unemployment with preterm delivery $(9,10)$, low birthweight (LBW) (11), small-for-gestational age (12), and a higher perinatal mortality rate (11), others have shown opposite results $(13,14)$. Additionally, deficiencies of trace elements, including copper and zinc, have been associated with maternal morbidity, such as hypertension (copper), infections, and diabetes mellitus (zinc) without significant effects on foetal outcomes (15). Adverse foetal outcomes have been recognized to constitute an important publichealth problem because several chronic diseases of public-health significance have been traced to adverse intrauterine and early life $(16,17)$. Although a high prevalence of deficiencies of trace elements 
(copper, iron, and zinc) has been reported among Nigerian pregnant women (18), there is a paucity of data on the role of maternal socioeconomic status on plasma levels of these trace elements and pregnancy outcomes. The present study was, therefore, conducted to determine the impact of maternal sociodemographic parameters on plasma iron, copper and zinc level and pregnancy outcomes in Nigerian pregnant women.

\section{MATERIALS AND METHODS}

\section{Study settings and sample}

The study was conducted among pregnant women attending the antenatal clinic of the Department of Obstetrics and Gynaecology of the Federal Medical Centre, Abakaliki, one of the referral tertiary health institutions in southeastern Nigeria, with an average delivery of 400 per annum. Abakaliki and the environs are inhabited mainly by subsistence-level population. Their main occupation is subsistence-level farming-mainly yam and cassava-with some animal husbandry. Other professions and/or activities, such as civil service, trading, artisanry, and stone quarrying, are also practised. The transmission of malaria is intense and occurs throughout the year (perennial). Three hundred and fifty-one consecutive women, aged 15-40 years (gestational age $\leq 25$ weeks), who gave their consent to participate in the study, were recruited during July 2007-September 2008. Women with chronic disease, women who were HIV-seropositive, and women with multiple pregnancies were excluded from the study.

Sets of structured questionnaire were used for collecting sociodemographic data of the participants. Their weights and heights (metre) were measured in light clothing without shoes and standing erect against a pre-marked scale attached to the weighing balance, and body mass index (BMI) $\left(\mathrm{kg} / \mathrm{m}^{2}\right)$ was calculated. Five $\mathrm{mL}$ of fasting venous blood collected at recruitment, during 08.00-10.00 hours, were dispensed into trace element-free heparinized plastic bottles $(3.0 \mathrm{~mL})$ and EDTA bottles (2.0.mL) for biochemical and haematological analyses. The heparinized blood samples were centrifuged at $2,000 \mathrm{~g}$ for five minutes for the isolation of plasma. The plasma samples were frozen until these were analyzed. The participants were regularly followed up, based on appointment with their consultants till delivery. At every follow-up, the attending obstetricians evaluated them for anaemia ( $\mathrm{Hb}<11.0$ g/dL) (19), hypertension (blood pressure $<140 / 90$ $\mathrm{mmHg}$ ), diabetes (fasting plasma glucose $>7.8$ $\mathrm{mmol} / \mathrm{L}$ ), infection due to Helicobacter pylori (seropositive to $H$. pylori antibody), concomitant illness, such as malaria (positive thin or thick film), upper respiratory tract infection (presence of cough/or catarrh), and urinary tract infection (UTI; positive urine protein, nitrite, and leucocytes). At delivery, baby's birth outcomes, such as weight, length, and head-circumference and for stillbirth, mode of delivery, and gestation age at delivery, were recorded. Birthweight was determined using an electronic weighing balance and recorded to the nearest 0.05 $\mathrm{kg}$ with the scale checked periodically throughout the study for accuracy while birth-length and headcircumference were determined by a measuring tape to the nearest $0.1 \mathrm{~cm}$. A baby was considered underweight if the birthweight was $\leq 2.5 \mathrm{~kg}$ (20) and preterm if delivered at $\leq 37$ weeks. Plasma copper, iron, and zinc were determined using atomic absorption spectrophotometric method while maternal haemoglobin concentration was estimated using cyanmethaemoglobin method (21). Plasma levels of $<5.0 \mu \mathrm{mol} / \mathrm{L}$ (zinc), $8.0 \mu \mathrm{mol} / \mathrm{L}$ (copper), and $10.0 \mu \mathrm{mol} / \mathrm{L}$ (iron) were considered low (22).

\section{Analysis of data}

All data, including sociodemographic and obstetrics data, were analyzed using the SPSS software for Windows (version 7.5). The differences between groups were compared using one-way analysis of variance (ANOVA). Data were expressed either as mean and standard deviation or proportion/percentage. The statistical significance was set at the $\mathrm{p}$ value of $\leq 0.05$.

\section{Ethical approval}

The Ethics and Research Committee of the Federal Medical Centre, Abakaliki, Nigeria, approved the protocol for this study.

\section{RESULTS}

Table 1 shows the general characteristics of the pregnant women recruited at $\leq 25$ weeks gestation and those of the neonates at delivery. Although 351 pregnant women were recruited, one (0.3\%) died early into the study, remaining 350 (99.7\%). Data of women were available but samples were obtained from 349 participants as one participant declined to participate. At delivery, data of 319 (91.4\%) women and their neonates were available. Data were either incomplete or were not available for the remaining $30(8.6 \%)$ women.

Although, in general, the women were not deficient in any of the three trace elements evaluat- 


\begin{tabular}{|lcccc|}
\hline \multicolumn{6}{|c|}{$\begin{array}{l}\text { Table 1.General characteristics of pregnant women at } \leq 25 \text { weeks gestation and their neonates at } \\
\text { delivery }\end{array}$} & No. & Mean & SD & Range \\
\hline Parameter & 350 & 27.04 & 4.75 & $15-40$ \\
\hline Age (years) & 350 & 27.3 & 4.3 & $17.8-42.6$ \\
BMI $\left(\mathrm{kg} / \mathrm{m}^{2}\right)$ & 350 & 1.41 & 1.46 & $0-4$ \\
Parity & 350 & 21.76 & 3.12 & $11-25$ \\
Gestational age (weeks) & 349 & 9.59 & 9.42 & $0.89-45.36$ \\
Copper $(\mu \mathrm{mol} / \mathrm{L})$ & 349 & 10.25 & 7.69 & $1.79-45.12$ \\
Iron $(\mu \mathrm{mol} / \mathrm{L})$ & 349 & 9.19 & 9.16 & $0.7-67.32$ \\
Zinc $(\mu \mathrm{mol} / \mathrm{L})$ & 349 & 10.21 & 1.26 & $6.5-13.3$ \\
Haemoglobin $(\mathrm{g} / \mathrm{dL})$ & 343 & 7.01 & 2.52 & $1-14$ \\
Antenatal attendance & 319 & 39.14 & 1.73 & $33-43$ \\
Duration of pregnancy (weeks) & 319 & 3.06 & 0.50 & $2.00-4.50$ \\
Birthweight (cm) & 319 & 50.93 & 4.66 & $41.0-80.0$ \\
Birth-length $(\mathrm{cm})$ & 319 & 33.66 & 2.68 & $26.0-48.0$ \\
Head-circumference $(\mathrm{cm})$ & & & \\
\hline BMI=Body mass index; SD=Standard deviation & & & \\
\hline
\end{tabular}

ed (mean 9.59 $\pm 9.42,10.25 \pm 7.69$, and 9.19 \pm 9.16 $\mu \mathrm{mol} / \mathrm{L}$ for copper, iron, and zinc respectively), the ranges of the trace elements varied from very low levels to very high concentrations, with copper, iron, and zinc concentrations from $0.89,1.79$, and $0.70 \mu \mathrm{mol} / \mathrm{L}$ to values as high as $45.36,45.12$, and $67.32 \mathrm{mmol} / \mathrm{L}$ respectively. The participants were generally anaemic with the mean haemoglobin concentration of $10.21 \pm 1.26$, which is lower than the $11.0 \mathrm{~g} / \mathrm{dL}$ cut-off point recommended by the World Health Organization.

Table 2 shows the impact of maternal parity and indices of maternal socioeconomic status (living accommodation, educational level, and occupation) on plasma copper, iron and zinc concentrations. Although there was no definite trend of the impact of parity and other indices of socioeconomic status on the plasma levels of copper, iron, and zinc among the pregnant women in this population, higher levels of these trace elements were found in economically-advantaged groups (e.g. women whose living accommodation were flats, women with secondary/tertiary education, and women who were civil servants/artisans), with lower plasma level found in multiparous women. Except for copper, the prevalence of lower plasma iron and zinc decreased with increased maternal education; these were not significant ( $>>0.05$ ). Only $25 \%$ of the women without formal education had low plasma iron and zinc (mean $6.89 \pm 0.79$ and $1.89 \pm 1.49$ $\mu \mathrm{mol} / \mathrm{L}$ respectively).

Without a definite trend, maternal morbidity during pregnancy was found to be significantly more in women with lower educational level, except for $H$. pylori infection which was reported in sig- nificantly $(\mathrm{p}<0.05)$ higher proportions in women with higher educational level (Table 3). No definite trend of the impact of maternal education on foetal outcomes was observed, although most adverse outcomes were absent in women without formal education (Table 3). In the same vein, neither maternal morbidities nor foetal outcomes showed any specific trend in relation to maternal living accommodation, although women whose living accommodation was single rooms experienced more concomitant illnesses than women from other living accommodations (Table 3).

With the exception of pregnancy-induced hypertension found in significantly $(\mathrm{p}<0.05)$ higher proportions in women whose occupation was civil service, women whose occupation was farming had a significantly higher prevalence of anaemia, $H$. pylori infection, and other concomitant illnesses (Table 3). Significantly more adverse foetal outcomes were recorded in women who were housewives and farmers when compared with women who were civil servants and artisans.

\section{DISCUSSION}

There seemed to be a wide nutritional disparity in this population as evidenced by wide variations in the levels of trace elements. Although the reason for this disparity is obscure, contamination of water source cannot be ruled out as contamination of water supply has been found to be one of the causes of acute toxicity of trace elements in the general population (23). Again, differential bioavailability of trace elements due to nutrient-nutrient interactions $(24,25)$ may be a contributory factor to the wide differences in concentrations of trace elements in 


\begin{tabular}{|c|c|c|c|c|c|c|c|}
\hline $\begin{array}{l}\text { Maternal } \\
\text { parameter }\end{array}$ & No. & Copper & Mean \pm SD & Iron & Mean \pm SD & Zinc & Mean \pm SD \\
\hline \multicolumn{8}{|l|}{ Parity } \\
\hline 0 & 140 & $82(58.6)$ & $3.14 \pm 1.71$ & $88(62.8)$ & $5.99 \pm 1.92$ & $68(48.6)$ & $2.71 \pm 1.21$ \\
\hline 1 & 66 & $36(54.5)$ & $3.48 \pm 2.02$ & $47(71.2)$ & $5.80 \pm 2.04$ & $27(40.9)$ & $2.84 \pm 1.18$ \\
\hline 2 & 53 & $35(66.0)$ & $3.44 \pm 1.88$ & $35(66.0)$ & $5.60 \pm 1.76$ & $19(35.8)$ & $2.78 \pm 1.14$ \\
\hline 3 & 40 & $23(57.5)$ & $2.96 \pm 1.73$ & $23(57.5)$ & $6.31 \pm 1.78$ & $24(60.0)$ & $2.36 \pm 1.13$ \\
\hline$>3$ & 50 & $27(54.0)$ & $3.29 \pm 1.78$ & $29(58.0)$ & $5.80 \pm 1.59$ & $22(44.0)$ & $2.45 \pm 1.06$ \\
\hline Total & 349 & $203(58.2)$ & $3.25 \pm 1.80$ & $222(63.6)$ & $5.90 \pm 1.85$ & $160(45.8)$ & $2.65 \pm 1.16$ \\
\hline \multicolumn{8}{|c|}{$\begin{array}{l}\text { Living } \\
\text { accommodation }\end{array}$} \\
\hline Single room & 189 & $115(60.8)$ & $3.30 \pm 1.90$ & $123(65.1)$ & $5.95 \pm 1.90$ & $82(43.4)$ & $2.63 \pm 1.18$ \\
\hline Flat & 135 & $72(53.3)$ & $3.33 \pm 1.72$ & $82(60.7)$ & $5.89 \pm 1.87$ & $64(47.4)$ & $2.71 \pm 1.19$ \\
\hline Bungalow & 24 & $15(62.5)$ & $2.40 \pm 1.80$ & $16(66.7)$ & $5.64 \pm 1.45$ & $13(54.2)$ & $2.57 \pm 0.97$ \\
\hline Total & 348 & $202(58.1)$ & $3.24 \pm 1.80$ & $221(63.5)$ & $5.90 \pm 1.85$ & $159(45.7)$ & $2.65 \pm 1.16$ \\
\hline \multicolumn{8}{|c|}{ Educational level } \\
\hline None & 8 & $5(62.5)$ & $2.03 \pm 0.74$ & $2(25)$ & $6.89 \pm 0.79$ & $2(25)$ & $1.89 \pm 1.49$ \\
\hline Primary & 42 & $24(57.1)$ & $2.79 \pm 1.65$ & $24(57.1)$ & $6.22 \pm 1.92$ & $17(40.5)$ & $2.59 \pm 1.13$ \\
\hline Secondary & 171 & $97(56.7)$ & $3.27 \pm 1.81$ & $111(64.9)$ & $6.02 \pm 1.86$ & $82(48.0)$ & $2.62 \pm 1.18$ \\
\hline Tertiary & 120 & $71(59.2)$ & $3.60 \pm 1.87$ & $80(66.7)$ & $5.59 \pm 1.82$ & $55(45.8)$ & $2.74 \pm 1.19$ \\
\hline Total & 341 & $197(57.8)$ & $3.30 \pm 1.81$ & $217(63.6)$ & $5.89 \pm 1.86$ & $156(45.8)$ & $2.65 \pm 1.17$ \\
\hline \multicolumn{8}{|l|}{ Occupation } \\
\hline Housewife & 53 & $31(58.5)$ & $3.45 \pm 1.90$ & $32(60.4)$ & $6.01 \pm 1.85$ & $28(52.8)$ & $2.77 \pm 1.18$ \\
\hline Student & 61 & $40(65.6)$ & $3.16 \pm 1.89$ & $40(65.6)$ & $5.99 \pm 1.80$ & $29(47.5)$ & $3.0 \pm 1.18$ \\
\hline $\begin{array}{l}\text { Civil } \\
\text { servant }\end{array}$ & 143 & $64(44.8)$ & $3.27 \pm 1.76$ & $92(64.3)$ & $5.77 \pm 1.83$ & $65(45.5)$ & $2.50 \pm 1.14$ \\
\hline Artisan & 87 & 44 (50.6) & $3.30 \pm 1.67$ & $56(64.4)$ & $5.89 \pm 1.94$ & $36(41.4)$ & $2.52 \pm 1.12$ \\
\hline Farmer & 5 & $4(80.0)$ & $3.20 \pm 1.62$ & $2(40.0)$ & $8.04 \pm 0.83$ & $2(40.0)$ & $3.19 \pm 1.99$ \\
\hline Total & 349 & $203(58.2)$ & $3.25 \pm 1.80$ & $222(63.6)$ & $5.90 \pm 1.85$ & $160(45.8)$ & $2.65 \pm 1.16$ \\
\hline
\end{tabular}

this population. This has important public-health implications for mothers and their infants as this may reflect in differential plasma levels of these elements and maternal and foetal outcomes.

This study has documented a significantly higher prevalence of maternal morbidities (malaria, upper respiratory tract infection (UTI), anaemia, UTI plus malaria) among women from disadvantaged socioeconomic status as represented by women whose occupation was farming, women without formal education or primary education, and women whose living accommodation was single room, thus suggesting that maternal socioeconomic status impacts negatively on maternal health during pregnancy. This is consistent with the significant roles played by psychosocial factors, such as poverty and socioeconomic status in pregnancy outcomes earlier reported by Chandra (1).

In developing countries, socioeconomic status is a complex term generally used for defining social inequalities and usually measured by income/educational level/occupation/living accommodation. However, maternal hypertension was recorded in a higher proportion of civil servants/artisans. This suggests that civil servants and women who were artisans in this environment were more exposed to risk factors for hypertension (including stress) than other occupational groups. Stress has been related to hormonal changes, and occupational strain may result in shortened duration of pregnancy and babies who were small for their gestational age $(26,27)$.

The role of social factors on pregnancy outcomes, such as preterm, LBW, spontaneous abortion, alterations in foetal development, and long-term health of offspring, have been widely acknowledged (1). Significantly more post-term deliveries among housewives, more surgical deliveries among housewives and civil servants, and significantly more deliveries of LBW babies among civil servants 


\begin{tabular}{|c|c|c|c|c|c|c|c|c|c|}
\hline \multirow{2}{*}{$\begin{array}{l}\text { Maternal } \\
\text { sociodemogra- } \\
\text { phic data }\end{array}$} & \multirow[b]{2}{*}{ Anaemia } & \multicolumn{4}{|c|}{ Maternal outcomes } & \multicolumn{4}{|c|}{ Foetal outcomes } \\
\hline & & Illnesses & H. pylori & HTN & $\overline{\mathrm{DM}}$ & $\begin{array}{l}\text { Assisted } \\
\text { delivery }\end{array}$ & $\begin{array}{l}\text { Surgical } \\
\text { delivery }\end{array}$ & LBW & Post-term \\
\hline \multicolumn{10}{|l|}{$\begin{array}{l}\text { Educational } \\
\text { level }\end{array}$} \\
\hline None & $87.5^{\dagger}$ & $37.5^{\dagger}$ & $25^{\dagger}$ & $14.3^{\dagger}$ & - & - & - & 12.5 & - \\
\hline Primary & $71.4^{\dagger \dagger}$ & $64.3^{\dagger \dagger}$ & $16.7^{\dagger \dagger}$ & $21.4^{\dagger \dagger}$ & $2.5 \dagger$ & $15.4^{\dagger \dagger}$ & $37.7^{\dagger}$ & 15.4 & 5.1 \\
\hline Secondary & $59.9 \mathbb{I}$ & $58.5^{\dagger \dagger}$ & $19.8^{\dagger \dagger}$ & 7.7 & $1.8 \mathbb{I}$ & $6.9^{\text {II }}$ & $5.0^{\dagger \dagger}$ & 12.0 & 8.2 \\
\hline Tertiary & $64.2 \mathbb{I}$ & $68.8^{\dagger \dagger}$ & $33.3 \mathbb{I}$ & $13.7^{\dagger}$ & $7.8 \S$ & $10.2 \dagger \dagger$ & $4.6 \dagger$ & 17.6 & 6.5 \\
\hline Total & 69.3 & 61.2 & 24.3 & 11.6 & 3.9 & 8.9 & 5.1 & 14.4 & 7.0 \\
\hline \multicolumn{10}{|l|}{$\begin{array}{l}\text { Living } \\
\text { accommodation }\end{array}$} \\
\hline Single room & 63.0 & $63.0^{\dagger}$ & 20.1 & 12.0 & 3.8 & $9.9^{\dagger}$ & $4.7^{\dagger}$ & $12.9^{\dagger}$ & 7.6 \\
\hline Flat & 65.2 & $61.0^{\dagger}$ & 29.6 & 11.1 & 3.8 & $8.7^{\dagger}$ & $5.5^{\dagger}$ & $12.6^{\dagger}$ & 6.3 \\
\hline Bungalow & 66.7 & $45.8^{\dagger \dagger}$ & 20.8 & 8.7 & 4.3 & $4.8^{\dagger \dagger}$ & $9.5^{\dagger \dagger}$ & $33.3^{\dagger}$ & 4.8 \\
\hline Total & 64.1 & 61.0 & 23.9 & 11.4 & 3.8 & 9.1 & 5.3 & 14.2 & 6.9 \\
\hline \multicolumn{10}{|l|}{ Occupation } \\
\hline Housewife & $56.6^{\dagger}$ & $64.2^{\dagger}$ & $22.6^{\dagger}$ & $3.8^{\dagger}$ & $1.9^{\dagger}$ & $5.9^{\dagger}$ & $7.8^{\dagger}$ & $18.0^{\dagger}$ & 10.0 \\
\hline Civil servant & $65.0 \dagger \dagger$ & $69.7 \dagger$ & $25.9^{\dagger}$ & $16.3^{\dagger \dagger}$ & $5.8 \dagger \dagger$ & $8.6^{\dagger}$ & $7.0^{\dagger}$ & $18.8^{\dagger}$ & 7.0 \\
\hline Artisan & $60.9 \dagger$ & $54.7 \dagger$ & $24.1^{\dagger}$ & $12.8^{\dagger \dagger}$ & $3.5 \mathscr{I}$ & $8.4^{\dagger}$ & $2.4^{\dagger \dagger}$ & $6.0 \dagger$ & 4.8 \\
\hline Student & $68.9 \dagger \dagger$ & $45.8 \mathbb{I}$ & $19.7^{\dagger}$ & $6.9^{\dagger}$ & $1.8^{\dagger}$ & $15.1^{\dagger \dagger}$ & $3.8^{\dagger \dagger}$ & $11.3 \mathbb{I}$ & 7.5 \\
\hline Farmer & 100.0I & $80.0 \S$ & $40.00^{\dagger \dagger}$ & - & - & - & - & $20.0^{\dagger}$ & - \\
\hline Total & 63.9 & 61.2 & 24.1 & 11.7 & 3.8 & 9.1 & 5.3 & 14.1 & 6.9 \\
\hline
\end{tabular}

and farmers respectively showed that housewives, farmers and civil servants were at increased risk of adverse foetal outcomes. While higher post-term delivery among housewives may be partly attributed to maternal inactivity, higher surgical delivery among housewives and civil servants may be due to maternal awareness and access to medical care (28). Delivery of LBW babies among farmers and civil servants may be partly attributed to either stress or/and nutritional deficiencies as evidenced by lower plasma levels of copper, iron, and zinc in women who were civil servants in the present study. It has been suggested that women who are employed as exemplified by civil servants/farmers may be at a risk of nutritional deficiencies because of reduced time for shopping and cooking (29). Moreover, working women who worked standing are less likely to eat three meals per day than women who worked in occupation that did not require long standing (30).

Deficit of trace elements, including zinc deficiency, has been associated with LBW (31). Additionally, increased physical activity, as measured by work in farms or fetching of water, for example, has been associated with LBW infants, smaller head-circumference, smaller mid-upper arm circumference, and lower placental weight (32). For example, maternal stress due to poverty is associated with preterm delivery via increased levels of epinephrine (33), increased oxytocin (34), and change in maternal habits (35).

Although maternal education did not display any trend in relation to maternal morbidities, the higher prevalence of maternal morbidities, such as anaemia, malaria, and UTI in women with lower educational level is in agreement with earlier studies (8). This is quite understandable as educational attainment has been established as a social variable that often displays the largest socioeconomic influence (36) because it affects both income and occupation. Educated women are also more likely to understand public-health message (37) and to maintain high personal hygiene than less-educated women. Educated women also belong to high social class and have access to adequate medicare and nutrition during pregnancy. However, a higher prevalence of $H$. pylori infection among women with higher educational level in the present finding supports the urban nature of the organism (38).

Ironical as it may sound, women without formal education had the lowest adverse foetal outcomes 
when compared with women with one form of education or the other. This is in contrast to other findings $(2,5)$ where women with the lowest education level had almost twice the odds of delivering a small-for-gestational age newborn compared to mothers in the highest education-category. The reason for this disparity is not clear but it may not be unconnected with the number of subjects $(\mathrm{n}=8)$ when compared with other groups. Koupilova et al. reported a birthweight gradient between women with primary and tertiary education (38).

A higher incidence of maternal morbidities and adverse foetal outcomes was reported in women whose living accommodation was a single room than other accommodation groups who also affirmed the role of maternal socioeconomic status on pregnancy outcomes. Although, in this population, living accommodation of women may not accurately indicate maternal socioeconomic status because of family dislocation due to job locations of spouses, women in lower socioeconomic strata have more adverse pregnancy outcomes (1).

In the present study, although maternal socioeconomic status appeared to influence maternal morbidity and pregnancy outcomes (via trace element nutriture), the effects were not clearly defined. This may be due to indices of maternal socioeconomic status used. For example, most women who were living in a single room were from higher educational level, and the reason given for such living accommodation was family dislocation as a result of job locations between couples. A high rate of unemployment may also contribute to invalidating maternal educational status - an indicator of socioeconomic status in the present study as some women educated to tertiary level still remained unemployed and lived in a single room. We, however, suggest that, in socioeconomically-disadvantaged population of developing countries, maternal occupation may be the more appropriate indicator for the assessment of maternal socioeconomic status.

\section{ACKNOWLEDGEMENTS}

The authors acknowledge the staff of the Department of Obstetrics and Department of Gynaecology and Medical Records of the Federal Medical Centre for logistic support.

\section{REFERENCES}

1. Chandra DC. Societal factors and pregnancy outcome (editorial). Nepal J Obstet Gynaecol 2008;3:1-3.

2. Morgen CS, Bjork C, Andersen PK, Mortensen LH, Andersen AMN. Socioeconomic position and the risk of preterm birth: a study within the Danish National Birth Cohort. Int J Epidemiol 2008;37:1109-20.
3. Aydemir F, Cavdar AO, Soylemez F, Cengiz B. Plasma zinc levels during pregnancy and its relationship to maternal and neonatal characteristics: a longitudinal study. Biolog Trace Element Res 2003;91:193-202.

4. Tuntiseranee P, Olsen J, Chongsuvivatwong V, Limbutara S. Socioeconomic and work related determinants of pregnancy outcome in southern Thailand. $J$ Epidemiol Communiy Health 1999;53:62429.

5. Parker JD, Schoendorf KC, Kiely JL. Association between measures of socioeconomic status and low birth weight, small-for-gestational age, and premature delivery in the United States. Ann Epidemiol 1994;4:271-8.

6. Steer P, Flint C. ABC of labour care: preterm labour and premature rupture of membrane BMJ 1999;318:105962.

7. Thompson JMD, Irgens LM, Rasmussen S, Dalveit AK. Secular trends in socio-economic status and the implications for preterm birth. Paediatr Perinat Epidemiol 2006;20:182-7.

8. Raum E, Arabin B, Schlaud M, Walter U, Schwartz FW. The impact of maternal education on intrauterine growth: a comparison of former West and East Germany. Int J Epidemiol 2001;30:81-7.

9. Ancel RL, Saurel-Cubizolles MJ, Di Renzo GC, Papiernik E, Breart G. Social differences of very preterm birth in Europe: interaction with obstetric history. Europop group. Am J Epidemiol 1999;149:90815.

10. Hanke W, Saurel-Cubizolles MJ, Sobala W, Kalinka J. Employment status of pregnant women in central Poland and the risk of preterm delivery and small-forgestational age infants. Eur J Public Health 2001;11:238.

11. Murphy JF, Dauncey M, Newcombe R, Garcia J, Elbourne D. Employment in pregnancy: prevalence, maternal characteristics perinatal outcome. Lancet 1984;1:1163-6.

12. Raatikainen K, Heiskanen N, Heinonen S. Does unemployment in family affect pregnancy outcomes in condition of high quality maternity care? BMC Public Health 2006;6:46.

13. Henriksen TB, Savitz DA, Hedegaard M, Secher NJ. Employment during pregnancy in relation to risk factors and pregnancy outcome Br J Obstet Gynaecol 1994;101:858-65.

14. Wildschut HI, Nas T, Golding J. Are sociodemographic factors predictive of preterm birth? A reappraisal of the 1958 British perinatal mortality survey. Br J Obstet Gynaecol 1997;104:57-63.

15. Ugwuja EI, Akubugwo EI, Ibiam AU, Obidoa O. Impact of maternal copper and zinc on pregnancy outcomes in a population of pregnant Nigerians. Pakistan J Nutr 2010;9:678-82. 
16. Ugwuja EI, Akubugwo EI, Ibiam AU, Obidoa O., Ugwu NC. Plasma copper and zinc among pregnant women in Abakaliki, southeastern Nigeria. Internet J Nutr Wellness 2010;10:1.

17. Ben SY, Kuh D. A life course approach to chronic disease epidemiology: conceptual models, empirical challenges and interdisciplinary perspectives. Int $J$ Epidemiol 2002;31:285-93.

18. Harding JE. The nutritional basis of the foetal origins of adult disease. Int J Epidemiol 2001;30:15-23.

19. World Health Organization. The prevalence of anaemia in women: a tabulation of available information. Geneva: World Health Organization, 1992:6.

20. Fawzi WW, Msamanga GI, Urassa W, Hertzmark E, Petraro PM. Willett WC et al. Vitamins and perinatal outcomes among HIV-negative women in Tanzania. New Engl J Med 2007;356:1423-31.

21. Dacie JV, Lewis SM. Practical haematology. 8th ed. Edinburg: Churchill Livingstone, 1994:49-59.

22. Robets WL, McMillin GA, Burtis CA, Bruns DE. Reference information for clinical laboratory. In: Burtis CA, Ashwood ER, Bruns DE, editors. Tietz Textbook of clinical chemistry and molecular diagnosis. 4 th ed. St. Louis, Missouri: Saunders, 2006:2251-302.

23. Bremner I. Manifestations of copper excess. Am J Clin Nutr 1998;67(5 Suppl):1069S-73S.

24. Sandstrom B. Micronutrient interactions: effects on absorption and bioavailability. Br J Nutr 2001;85(Suppl 2):S181-5.

25. Turnlund JR. Copper. In: Shils ME, Shike M, Ross AC, Caballero B, Cousins RJ, editors. Modern nutrition in health and disease. 10th ed. Philadelphia: Lippincott Williams \& Wilkins, 2006:286-99.

26. Kramer MS, Goulet L, Lydon J, Seguin L, McNamara $\mathrm{H}$, Dassa C et al. Socio-economic disparities in preterm birth: causal pathways and mechanisms. Paediatr Perinat Epidemiol 2001;15(Suppl 2):104-23.

27. Henriksen TB, Hedegaard M, Secher NJ. The relation between psychosocial job strain, and preterm delivery and low birthweight for gestational age. Int J Epidemiol 1994;23:764-74.
28. Filho FL, Assunção AN, Jr., Silva AAM, Lamy ZC, Barbieri MA, Bettilo H. Social inequality and perinatal health: comparison of three Brazilian cohorts. Brazilian J Med Biolog Res 2007;40:1177-86.

29. Zuckerman BS, Frank DA, Hingson R, Morelock S, Kayne HL. Impact of maternal work outside the home during pregnancy on neonatal outcome. Paediatr 1986;77:459-64.

30. Arntzen A, Andersen AM. Social determinants for infant mortality in the Nordic countries 1980-2001. Scand J Public Health 2004;32:381-9.

31. Pathak P, Kapil U. Role of trace elements zinc, copper and magnesium during pregnancy ant its outcomes. Indian Paediatr 71:1003-5.

32. Shaw GM. Strenuous work, nutrition and adverse pregnancy outcomes: a brief review. J Nutr 2003; 133:1718S-721S.

33. Lobel M, Dunkel-Schetter C, Scrimshaw SCM. Prenatal maternal stress and prematurity: a prospective study of socio-economically disadvantaged women. Health Psychol 1992;11:32-40.

34. Wadhuta PD, Sandman CA, Porto M, Dunkel-Schetter C, Garite TJ. The association between prenatal stress and infant birthweight and gestational age at birth: a prospective investigation. Am J Obstet Gynaecol 1993;169:858-65.

35. Khashan KS, Mcnamee RM, Abel KM, Mortensen PB, Kenny LC, Pedersen MG et al. Rates of preterm birth following antenatal maternal exposure to severe life events: a population-based cohort study. Human Reproduct 2009;24:429-37.

36. Andersen AMN, Mortensen LH. Socioeconomic inequality in birth outcomes: what do the indicators tell us, and where do we find the data. CMAJ 2006;174:1429-30.

37. Ugwuja EI, Ugwu NC. Helicobacter pylori in uninvestigated dyspepsia in primary health cares in Abakaliki, Nigeria. Online J Health Allied Sci 2007;1:4.

38. Koupilova I, Bobak M, Holcik J, Pikhart H, Leon DA. Increasing social variation in birth outcomes in the Czeh Republic after 1989. Am J Public Health 1998;88:1343-7. 